\title{
Statin prescribing among hypertensive patients in south-west Nigeria; findings and implications for the future
}

\author{
Onyinye Onyeka Akunne1, "Brian Godman²,3, Aduragbenro Deborah Adedapo', Ilse Truter ${ }^{4}$, Joseph \\ Fadare $^{5}$ \\ 1Department of Pharmacology and Therapeutics, University of Ibadan, Nigeria. Email: \\ onyinyeakunne@yahoo.com, debyee1965@yahoo.co.uk \\ 2,3Brian Godman, Department of Laboratory Medicine, Division of Clinical Pharmacology, \\ Karolinskalnstitutet, Karolinska University Hospital Huddinge, SE-141 86, Stockholm, Sweden. Email: \\ Brian.Godman@ki.se and Strathclyde Institute of Pharmacy and Biomedical Sciences, University of \\ Strathclyde, Glasgow, UK. Email:Brian.godman@strath.ac.uk \\ ${ }^{4}$ Drug Utilization Research Unit (DURU), Department of Pharmacy, Nelson Mandela Metropolitan \\ University, Port Elizabeth 6031, South Africa. Email: Ilse.Truter@nmmu.ac.za \\ ${ }^{5}$ Department of Pharmacology, Ekiti State University, Ado-Ekiti, Nigeria. Email: jofadare@gmail.com,
}

Address for correspondence:

*Brian Godman, Department of Laboratory Medicine, Division of Clinical Pharmacology, Karolinska Institute, Karolinska University Hospital Huddinge, SE-141 86, Stockholm, Sweden.

Email: Brian.Godman@ki.se

Keywords: Statins, hypertension, Nigeria, generics, costs

(Journal of Comparative Effectiveness Research. DOI: 10.2217/CER.15.65 In Press. Please keep CONFIDENTIAL)

\begin{abstract}
Background:: Statins reduce cardiovascular risk especially in patients with hypertension due to their concomitant blood pressure reducing effects. Prescribing generic statins minimizes cost and improves access. Aims: Ascertain current prescribing of statins in Nigeria and potential savings from the increased use of generics. Methods: Prospective study involving hypertensive patients attending University College Hospital, Ibadan, Nigeria. Results: 228 hypertensive patients received statins. Atorvastatin was the most prescribed statin, followed by simvastatin, rosuvastatin and finally fluvastatin. Prescribed doses were less than 1 defined daily dose in the majority, with high use of originators. Average monthly potential savings from increased prescribing of generics was US $\$ 2,635$ for atorvastatin and US\$10578 for rosuvastatin. Conclusions: A shift towards increased prescribing generics is recommended to minimize costs
\end{abstract}

\section{Introduction}

Hypertension is a major public health concern with enormous financial implications to individuals, governments and third party payers [1-3]. It is a risk factor for development of cardiovascular diseases, which is a leading cause of morbidity and mortality worldwide [4]. The presence of elevated total and low density lipoprotein in hypertensive patients further increases cardiovascular risk [5]. Statins (3-hydroxy 3-methyl glutaryl co-enzyme A (HMG-COA) reductase inhibitors) are first-line treatment for patients with cardiovascular risk and elevated serum cholesterol [6-8] . Statins are particularly useful for treating hypercholesterolemia in hypertensive patient because of their concomitant blood pressure reducing effects [9-11]. These effects have been largely attributed to their reported ability to improve arterial compliance, increase bioavailability of nitric oxide, improve endothelial-dependent vasodilation and reduce levels of endothelin-1, which is a potent vasoconstrictor [12-15]. Down regulation in the expression of angiotensin type 1 (AT1) receptors, p22 $2^{\text {phox }}$-a NADPH oxidase subunit, and a reduction of free radical release in the vasculature by statins also reduces blood pressure [16, 17]. Consequently, statins should be prescribed alongside medicines to treat hypertension to reduce morbidity and mortality in patients with cardiovascular disease including hypertension [8] .

Recent studies have shown limited difference in the effectiveness of different statins at therapeutic doses, no difference in the effectiveness between generic and originator (brand name) statins and 
successful switching of patients between higher priced patented and generic statins to save considerable resources without compromising care [18-21]. Cost considerations are increasingly important especially with the growing prevalence of non-communicable diseases including diabetes, hypertension, and obesity and generic statins priced as low as $2 \%$ to $4 \%$ of pre-patent loss prices in some countries $[3,22-24]$.

Cost considerations are particularly important in Nigeria where over $90 \%$ of the population are not covered by any form of health insurance and out of pocket spending (OOP) can be as high as $62 \%$ of total healthcare expenditure [25-28]. Typically only medicines for patients with HIV/ AIDS are free of charge as these are provided by donors. All others are bought by patients (OOP) if they do not have access to health insurance. However, high patient co-payments potentially impact on available medicine choices as well as affecting long term compliance [29, 30].

In Nigeria, the National Agency for Food and Drug Administration (NAFDAC) is the main regulatory body for medicines including generics [31[, and current regulations stipulate that prescriptions should be made using the international non-proprietary name (INN) [32], endorsing practices in other countries, e.g. Lithuania and the United Kingdom [22, 33]. However, there are no formal regulations for the pricing of generics in Nigeria unlike Europe [34,35], which has resulted in higher prices for generics in Nigeria compared with the UK, e.g. for generic SSRIs [36]. In addition, there are concerns with the quality of generics among physicians in Nigeria, especially locally produced generics, potentially impacting on their prescribing in practice [37]. There are also concerns with the doses of statins prescribed in the management of patients with cardiovascular disease, especially simvastatin, e.g. the average dose of simvastatin for secondary prevention in patients in Ireland was only $22 \mathrm{mg}$ with a number of other studies showing similar low doses of simvastatin being prescribed [38, 39].

Consequently, there is a need to assess the level of prescribing of generic versus originator and patented statins in Nigeria, the doses prescribed as well as their costs, to ascertain the current rationality of the prescribing of statins in Nigeria. Any underdosing of statins needs to be urgently addressed as this significantly increases patients' risk of developing or progressing their cardiovascular disease with reduced cardioprotection [40]. In addition, putting them at risk for heart attack or stroke [41].The findings from the study will be used to suggest pertinent measures and initiatives that could be introduced in Nigeria to improve rational prescribing of statins. Alongside this, obtain lower costs for generic statins if this proves to be a concern. These are the multiple aims of this study. To the best of our knowledge, this is the first study in Nigeria to assess all these parameters.

\section{Method}

Hypertensive patients attending three out-patient clinics of the University College Hospital (UCH), Ibadan, South-west Nigeria between November 2011 and April 2012 were enrolled prospectively into the study after obtaining ethical approval from the hospital Institutional Ethics Review Board.

Consecutive hypertensive patients with or without complications and co-morbidities attending the clinics, who had been diagnosed with high serum cholesterol levels, were enrolled into the study. Patients' demographic information, prescribed statins grouped according to originator or generic, and prescribed doses were collected from their medical records after each clinic visit.

The prescribed doses were subsequently compared with the defined daily dose (DDD) for each statin to assess potential underdosing, with DDDs defined as 'the average maintenance dose of a drug when used in its major indication in adults'. This measure is recognised as the international standard to assess utilisation patterns within and between countries (42).Current DDDs were used in line with recommendations $[42,43]$. This is similar to the methodology employed to assess current dosing of statins in other studies $[38,44]$.

The prices of medications at the time of prescription were obtained from the hospital pharmacy. Where there were omissions in the cost of any statin in the hospital price lists due to non-availability of the statins in hospital pharmacies, the costs of the statins from pharmacies near the hospital were used. This is under the assumption that patients will patronize nearby pharmacies where their prescribed medicines are currently unavailable in hospital pharmacies due to supply issues. Costs of prescribed statins were computed according to the strength prescribed, with the local currency (Naira) converted to US dollars at rates obtainable during study period i.e. $\$ 160$ per US\$. These exchange 
rates were chosen due to considerable changes in the conversion rates from Naira to US\$ especially in recent times. As a result, factor out major shifts in exchange rates, potentially distorting the findings. Finally, a comparison was made between current statin prescribing and potential costs if there were $100 \%$ generic statin prescribing to determine the extent of potential cost savings from increasing prescribing of generics.

A chi-squared analysis was performed for certain parameters, e.g. any differences in the prescribing of originators (brand named) medicines in male versus female physicians, with $p<0.05$ representing significance.

\section{Results}

Statins were prescribed to 228 patients enrolled into the study with males (106) constituting $46.5 \%$ of patients and females (122) 53.5\%. 52 patients had heart-related diseases, 60 had diabetes, with 20 having renal diseases. Most patients were aged between 50 and 70 years, with the ages ranging from 33 to 85 years with a mean age of $60 \pm 10$ years.

Originator drugs were mostly prescribed (67\%) among the statins except for simvastatin, which was prescribed by generic name only (Table 1 ).

Table 1: Distribution of statins prescribed to hypertensive patients between November 2011 to April 2012 (Brackets refer to the \% of the total number of patients)

\begin{tabular}{|c|c|c|c|c|c|c|c|c|c|c|c|c|}
\hline \multirow[t]{3}{*}{ Statin } & \multicolumn{12}{|c|}{ Dose per day $(\mathrm{mg})$} \\
\hline & & \multirow[t]{2}{*}{5} & \multirow[t]{2}{*}{10} & \multirow[t]{2}{*}{20} & \multirow[t]{2}{*}{25} & \multirow[t]{2}{*}{30} & \multirow[t]{2}{*}{40} & \multirow[t]{2}{*}{80} & \multirow{2}{*}{ Missing } & \multicolumn{3}{|c|}{ Total } \\
\hline & & & & & & & & & & M (\%) & $\mathrm{F}(\%)$ & All (\%) \\
\hline \multirow[t]{2}{*}{ Atorvastatin } & Originator & 1 & 64 & 36 & - & 1 & 2 & - & 2 & $\begin{array}{c}56 \\
(24.6)\end{array}$ & $\begin{array}{c}50 \\
(21.9)\end{array}$ & $\begin{array}{c}106 \\
(46.5)\end{array}$ \\
\hline & Generic & - & 18 & 3 & - & - & - & - & - & 9 (3.9) & $\begin{array}{c}12 \\
(5.3)\end{array}$ & $21(9.2)$ \\
\hline \multirow[t]{2}{*}{ Fluvastatin } & Originator & - & - & 5 & - & - & - & 2 & - & $1(0.4)$ & $6(2.6)$ & $7(3.1)$ \\
\hline & Generic & - & - & 1 & - & - & - & - & - & $1(0.4)$ & 0 & $1(0.4)$ \\
\hline \multirow[t]{2}{*}{ Rosuvastatin } & Originator & 36 & 3 & 1 & - & - & - & - & - & $\begin{array}{c}22 \\
(9.6)\end{array}$ & $\begin{array}{c}18 \\
(7.9)\end{array}$ & $\begin{array}{c}40 \\
(19.5)\end{array}$ \\
\hline & Generic & 1 & 1 & - & - & - & - & - & - & 0 & $2(0.9)$ & $2(0.9)$ \\
\hline Simvastatin & Generic & 1 & 14 & 27 & 1 & - & 6 & 1 & 1 & $\begin{array}{c}17 \\
(7.5)\end{array}$ & $\begin{array}{c}34 \\
(14.9)\end{array}$ & $\begin{array}{c}51 \\
(22.4)\end{array}$ \\
\hline
\end{tabular}

Atorvastatin was the most prescribed statin, followed by simvastatin and rosuvastatin (Table 1), with fluvastatin the least prescribed statin. There was greater prescribing of originator statins among males, although the difference between the two groups was not statistically significant. Lovastatin and pravastatin were not included in this study as typically these two statins are not currently marketed in Nigeria and not stocked by the hospitals as not on the formulary. Physicians need a strong rationale for prescribing outside the current formulary.

The prescribed doses were low compared to current DDDs. 13 patients were prescribed statins at doses greater than $1 \mathrm{DDD}$, whilst 45 prescriptions were at doses equal to 1 DDD and 167 patients were prescribed doses less than $1 \mathrm{DDD}$. The mean DDD was $0.66 \pm 0.33$ with a range equal to 0.17 to 2,67 DDDs (Males $=0.71 \pm 0.38$ and Females $=0.63 \pm 0.29)($ Table 2$)$. 
Table 2: Comparison of prescribed daily dose of statins with daily defined doses among hypertensive patients between November 2011 to April 2012 (figures $=\%$ of the total number of patients)

\begin{tabular}{|l|l|c|c|c|c|c|}
\hline $\begin{array}{l}\text { Statin and } \\
\text { their DDD }\end{array}$ & & <DDD (\%) & = DDD (\%) & >DDD (\%) & $\begin{array}{c}\text { Missing } \\
\text { (\%) }\end{array}$ & Total (\%) \\
\hline $\begin{array}{l}\text { Atorvastatin } \\
(20 \mathrm{mg})\end{array}$ & Originator & $65(28.5)$ & $36(15.8)$ & $3(1.3)$ & $2(0.9)$ & $106(46.5)$ \\
\cline { 2 - 7 } & Generic & $18(7.9)$ & $3(1.3)$ & - & - & $21(9.2)$ \\
\hline $\begin{array}{l}\text { Fluvastatin } \\
(60 \mathrm{mg})\end{array}$ & Originator & $5(2.2)$ & - & $2(0.9)$ & - & $7(3.1)$ \\
\cline { 2 - 7 } & Generic & $1(0.4)$ & - & - & - & $1(0.4)$ \\
\hline $\begin{array}{l}\text { Rosuvastatin } \\
(10 \mathrm{mg})\end{array}$ & Originator & $36(15.8)$ & $3(1.3)$ & $1(0.4)$ & - & $40(17.5)$ \\
\cline { 2 - 7 } & Generic & $1(0.4)$ & $1(0.4)$ & - & - & $2(0.9)$ \\
\hline $\begin{array}{l}\text { Simvastatin } \\
(30 \mathrm{mg})\end{array}$ & Generic & $43(18.9)$ & - & $7(3.1)$ & $1(0.4)$ & $51(22.4)$ \\
\hline & & & & & & $228(100)$ \\
\hline
\end{tabular}

*DDD= Daily defined dose

The total monthly costs for the statins were US\$6613 ( $\$ 1,058,040)$ (Table 3). This was highest for atorvastatin as it was the most prescribed statin; however, fluvastatin was the most expensive statin

Table 3 Total average statin costs per month in US\$ and Naira and US\$

\begin{tabular}{|l|c|c|}
\hline Statin & $\begin{array}{c}\text { Total monthly cost for all } \\
\text { patients (US\$ and N) }\end{array}$ & $\begin{array}{c}\text { Average monthly cost/ patient } \\
\text { (US\$ and N) }\end{array}$ \\
\hline Atorvastatin & $\$ 4,082(\$ 653,100)$ & $\$ 32.14(\$ 5,142.52)$ \\
\hline Fluvastatin & $\$ 512(\$ 81,990)$ & $\$ 64.00(\$ 10,248.75)$ \\
\hline Rosuvastatin & $\$ 1,485(\$ 237,600)$, & $\$ 35.36(\$ 5,657.14)$ \\
\hline Simvastatn & $\$ 533(\$ 85,350)$ & $\$ 10.45(\$ 1,673.53)$. \\
\hline All statins & $\$ 6,613(\$ 1,058040)$ & $\$ 29.00(\$ 4640.53)$ \\
\hline
\end{tabular}

The differences in the total monthly cost of generics and originators for atorvastatin, fluvastatin and rosuvastatin (Table 3 ) reflect differences in their cost per patient (generic and originator) (Table 4) as well as the prescribed dose (Table 2).

The average monthly costs of statins per mg per patient varied between US\$11.08 (\$1772) for simvastatin where only generics were dispensed to US\$73.13 (\$11,700) for originator fluvastatin (Table 4).

Table 4 - Total monthly cost per patient and per $\mathrm{mg}$ for originator and generic statins in Naira and $\underline{\text { US\$ }}$

\begin{tabular}{|l|c|c|}
\hline Statin & $\begin{array}{c}\text { Total monthly cost of } \\
\text { originators/mg/patient } \\
\text { US\$ (NGN) }\end{array}$ & $\begin{array}{c}\text { Total monthly cost of } \\
\text { generics/mg/patient } \\
\text { US\$ } \mathbf{~ ( N G N ) ~}\end{array}$ \\
\hline Atorvastatin & $38.18(6109.50)$ & $9.64(1542.90)$ \\
\hline Fluvastatin & $73.13(11700.00)$ & $16.88(2700.00)$ \\
\hline Rosuvastatin & $35.30(5647.50)$ & $13.36(2137.50)$ \\
\hline Simvastatin & - & $11.08(1772.00)$ \\
\hline
\end{tabular}

As a result of the differences in the prices of generics and originators for the various statins (Table 4), the average potential savings per month from the total prescribing of generics at the ascertained prices for each statin (Table 4) to the 228 hypertensive patients with hypercholesterolemia was US\$2,635 ( $\$ 421575.00$ ) for atorvastatin, US\$1,058 ( $\$ 169$ 275.00) for rosuvastatin and U\$276 ( $\$ 44$ 190.00) for fluvastatin (Figure 1). 
Figure 1: Potential cost savings (US\$) per month from prescribing generic statins to the 228 hypertensive patients with hypercholesterolemia between November 2011 to April 2012

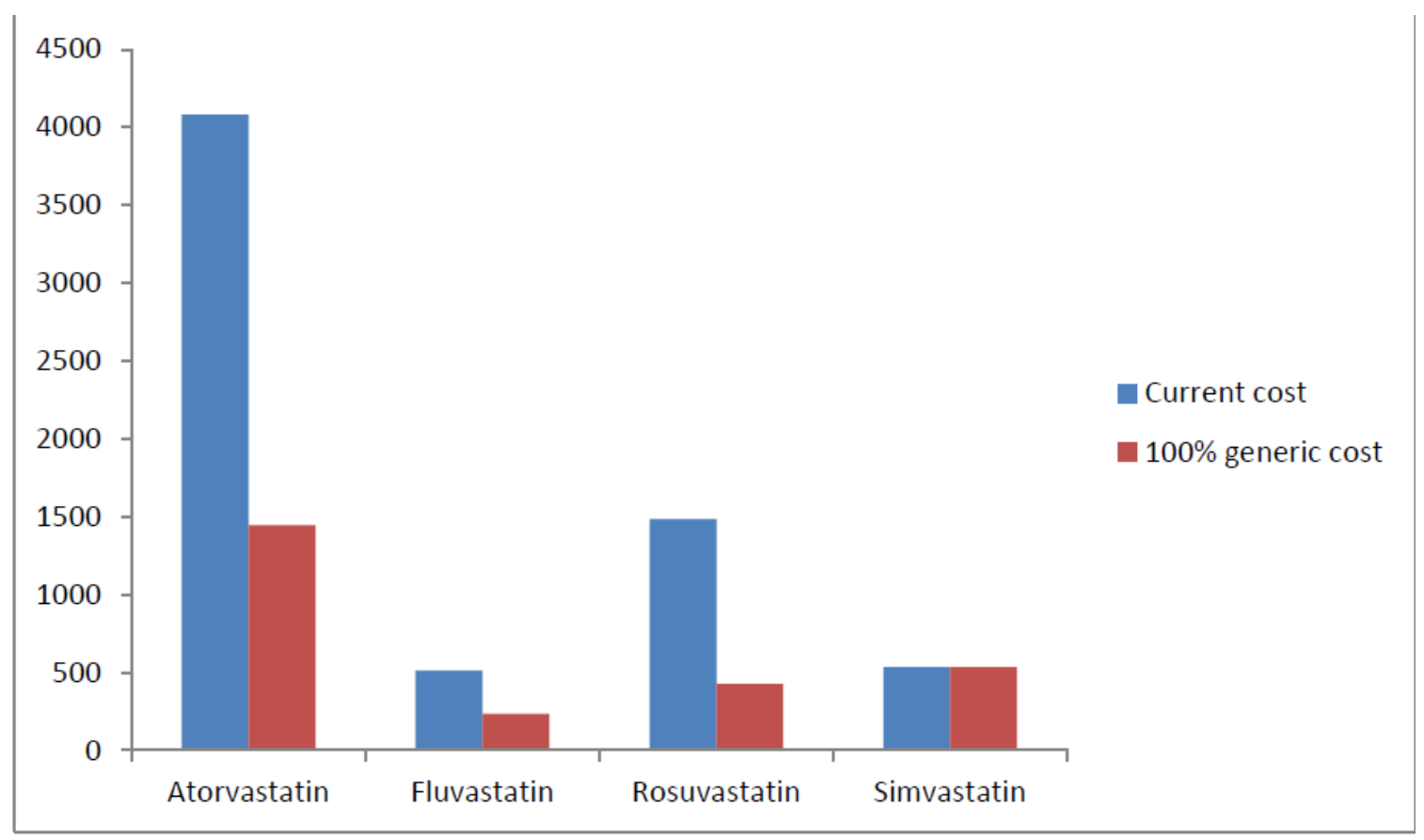

\section{Discussion}

It was encouraging to see that simvastatin was prescribed exclusively as the generic version. Overall though originators were prescribed more often than generics, despite generics being available for each statin (Table 2), which is a concern.. The appreciable prescribing of originators may be due to several factors. These include prescribers' knowledge about generics as well as concerns with their effectiveness and safety in routine clinical care including locally produced generics [37]. This will be the subject of future research given the opportunity for considerable savings (Figure 1).

The appreciable prescribing of both originator atorvastatin and rosuvastatin drove up the monthly cost of statins (Table 3). As a result, there were appreciable opportunities for savings in Nigeria with increased prescribing and dispensing of generics for these two statins versus the originators (Table 4 and Figure 1). Prescribing of generics instead of originators among all the statins except for simvastatin would have yielded $60 \%$ savings.

The greater use of atorvastatin, principally as the originator (brand named medicine), compared with simvastatin may be due to the long length of time since patent expiration coupled with aggressive marketing [45]. Marketing activities may also account for the appreciable use of rosuvastatin (Table 3). However, we cannot say this with certainty as the reasons behind the choice of statin and its presentation (originator or generic) was not explored in this research project.

Strategies to increase the prescribing of generic versus originator statins include greater encouragement of INN prescribing in line with current regulations [32]. This could be achieved through a number initiatives including education of physicians regarding INN prescribing starting in medical school, regular benchmarking of physician prescribing habits and potentially financial incentives for physicians for greater prescribing of generics [22, 46]. Such measures have achieved $98 \%$ to $99 \%$ INN prescribing in the UK for cardiovascular medicines including renin-angiotensin inhibitors and statins [22], providing a goal for the authorities in Nigeria. Other measures could include substitution targets for pharmacists or mandatory generic substitution $[23,46]$. However, physicians in Nigeria currently have concerns with generic substitution because of concerns with their quality including bioequivalence [37]. As a result there needs to be strategies to re-assure physicians about the quality of generics through for instance measures to ensure the instigation of good manufacturing practices for locally sourced and imported generics in Nigeria to meet the strict bioequivalence criteria 
seen in Europe before they receive marketing authorisation [47]. These strategies are important to ensure that patients receive the full health benefit from generic medicines including generic statins.

The prescribed daily doses of statins were lower than the DDD (Table 2) especially for simvastatin with only 8 patients prescribed the DDD or above (Table 2). Only six out of the 51 patients prescribed 40mg simvastatin (Table 2), which is the recommended dose in Scotland for patients with heart disease and diabetes [22]. Strategies to address this include greater education among physicians as well as potentially monitoring lipid levels in practice. These combined activities, together with financial incentives for physicians, led to increased prescribing of higher strength statins in the UK $[22,48]$.

Finally, the costs of generic statins appear to be appreciably higher in Nigeria that seen in for instance Netherlands, Sweden or the UK (Table 4). In these countries, monthly costs of 20 to $40 \mathrm{mg}$ generic simvastatin are approximately US $\$ 2$ to US $\$ 5 /$ month [22-24]. These differences could be explained by the 'open market' policy for pharmaceuticals in Nigeria with currently no attempt to regulate the prices of pharmaceuticals. Obtaining lower costs for statins through some form of government intervention will generate additional savings for patients and the healthcare system, building on those already outlined (Figure 1). Potential interventions could be in the form of tax breaks, reductions in import duties as well as requesting greater transparency in the pricing of pharmaceuticals including generics. As a result, potentially more patients will be able to comply with their prescriptions given the chronic nature of cardiovascular disease.

We are aware that there are a number of limitations with this study. Firstly, only 228 patients were enrolled. In addition, we only concentrated on three clinics at $\mathrm{UCH}$ in Ibadan, Nigeria. We were also not able to obtain costing data for from hospital pharmacists for all statins prescribed. This was the case for fluvastatin but not the other statins. Lastly, we did not explore the reasons behind the prescribing of originators versus generics or the reasons behind the doses of statins prescribed. Never-the-less, we feel this is a valid study suggesting considerable opportunities to improve the quality and efficiency of statin prescribing in the future. This includes lowering OOP for patients reducing the financial burden of chronic cardiovascular diseases. We will be exploring these issues in future research projects including potential strategies to obtain lower prices for generics in Nigeria similar to the situation in the Netherlands, Sweden and the UK.

\section{Conclusion}

We have shown that there are considerable opportunities to improve both the quality and efficiency of statin prescribing in Nigeria through increasing the doses of statin prescribed as well as encouraging increased prescribing of generics. There are also potential opportunities to obtain lower prices of generics. These will be the subject of further research projects.

\section{Acknowledgements and financial interests}

We would like to acknowledge the support of Professor BL Salako, Nephrology Unit, and Dr Olulola Oladapo, Cardiology Unit, at the University College Hospital, Ibadan, Nigeria, for allowing access to their clinics and patients for the study. In addition, Dr Achiaka Irabor of the General Outpatient Clinic for support for the study.

There was no external financial support for this study (sponsored by one of the co-authors - OA) The write up of this paper was in part support by VR-Link grant from Swedish Research Council (VRLink 2013-6710).

There are no conflicts of interest from any author.

\section{Executive Summary}

- Statins are first line treatment for patients with hypercholesterolemia to reduce future cardiac event rates

- In patients with hypertension, they also reduce blood pressure, enhancing their role in patients with cardiovascular disease 
- All statins are seen as essentially similar at therapeutic doses, with no published difference in the effectiveness between generics and originators. Generic statins are also considerably cheaper than originators or patented statins in a class

- There was appreciable use of originator versus generic statins in Nigeria despite high out-ofpocket payments. In addition, prescribed doses of statins were generally sub-optimal (based in defined daily doses)

- Educational initiatives are needed to increase the doses of statins prescribed to reduce patients' risks of developing or progressive their cardiovascular disease. Increased prescribing of generic statins will benefit both patients and the healthcare system.

- There are opportunities to further lower prices of generic statins in Nigeria towards those seen among some European countries. As a result, save further expenditure for the healthcare system and patients

\section{References}

1. Modesti PA, Agostoni P, Agyemang $\mathrm{C}$ et al. Cardiovascular risk assessment in low-resource settings: a consensus document of the European Society of Hypertension Working Group on Hypertension and Cardiovascular Risk in Low Resource Settings. Journal of hypertension. 2014;32(5):951-60.

2. Volpe M, Tocci G. 2007 ESH/ESC Guidelines for the management of hypertension, from theory to practice: global cardiovascular risk concept. Journal of hypertension Supplement. 2009;27(3):S3-11.

3. Kaplan W, Wirtz V, Mantel-Teeuwisse A, Stolk P, Duthey B, Laing R. Priority Medicines for Europe and the World 2013 Update Report. Available at URL: http://www.who.int/medicines/areas/priority medicines/MasterDocJune28 FINAL Web.pdf?ua=1. 4. Wachtell K, Devereux RB, Lyle PA, Okin PM, Gerdts E. The left atrium, atrial fibrillation, and the risk of stroke in hypertensive patients with left ventricular hypertrophy. Therapeutic advances in cardiovascular disease. 2008;2(6):507-13.

5. Ferdinand KC, Kleinpeter MA. Management of hypertension and dyslipidemia. Current hypertension reports. 2006;8(6):489-96.

6. Stone NJ, Robinson JG, Lichtenstein AH et al. 2013 ACC/AHA guideline on the treatment of blood cholesterol to reduce atherosclerotic cardiovascular risk in adults: a report of the American College of Cardiology/American Heart Association Task Force on Practice Guidelines. Circulation. 2014;129(25 Suppl 2):S1-45.

7. Klose G, Beil FU, Dieplinger $\mathrm{H}$ et al. New AHA and ACC guidelines on the treatment of blood cholesterol to reduce atherosclerotic cardiovascular risk. Wiener klinische Wochenschrift. 2014;126(5-6):169-75.

8. Perk J, De Backer G, Gohlke H et al. European Guidelines on cardiovascular disease prevention in clinical practice (version 2012). The Fifth Joint Task Force of the European Society of Cardiology and Other Societies on Cardiovascular Disease Prevention in Clinical Practice (constituted by representatives of nine societies and by invited experts). European heart journal. 2012;33(13):1635-701.

9. Koh KK, Quon MJ, Waclawiw MA. Are statins effective for simultaneously treating dyslipidemias and hypertension? Atherosclerosis. 2008;196(1):1-8.

10. King DE, Mainous AG, Egan BM, Player M, Geesey ME. Use of statins and blood pressure. American journal of hypertension. 2007;20(9):937-41.

11. Morgado M, Rolo S, Macedo AF, Castelo-Branco M. Association of statin therapy with blood pressure control in hypertensive hypercholesterolemic outpatients in clinical practice. Journal of cardiovascular disease research. 2011;2(1):44-9.

*Demonstrates lowering of blood pressure with statins 
12. Leibovitz E, Hazanov N, Zimlichman R, Shargorodsky M, Gavish D. Treatment with atorvastatin improves small artery compliance in patients with severe hypercholesterolemia. American journal of hypertension. 2001;14(11 Pt 1):1096-8.

13. Ferrier KE, Muhlmann MH, Baguet JP et al. Intensive cholesterol reduction lowers blood pressure and large artery stiffness in isolated systolic hypertension. Journal of the American College of Cardiology. 2002;39(6):1020-5.

14. Haug C, Schmid-Kotsas A, Zorn U et al. Endothelin-1 synthesis and endothelin B receptor expression in human coronary artery smooth muscle cells and monocyte-derived macrophages is upregulated by low density lipoproteins. Journal of molecular and cellular cardiology. 2001;33(9):170112.

15. Tycinska AM, Janica J, Mroczko B et al. Hypotensive effect of atorvastatin in hypertensive patients: the association among flow-mediated dilation, oxidative stress and endothelial dysfunction. Archives of medical science : AMS. 2011;7(6):955-62.

16. Nickenig G, Baumer AT, Temur Y, Kebben D, Jockenhovel F, Bohm M. Statin-sensitive dysregulated AT1 receptor function and density in hypercholesterolemic men. Circulation. 1999;100(21):2131-4.

17. Wassmann S, Laufs U, Baumer AT et al. HMG-CoA reductase inhibitors improve endothelial dysfunction in normocholesterolemic hypertension via reduced production of reactive oxygen species. Hypertension. 2001;37(6):1450-7.

18. Weng TC, Yang YH, Lin SJ, Tai SH. A systematic review and meta-analysis on the therapeutic equivalence of statins. Journal of clinical pharmacy and therapeutics. 2010;35(2):139-51.

** Good meta analysis showing limited difference in effectiveness bewteen the statins at therapeutic doses

19. Usher-Smith J, Ramsbottom T, Pearmain H, Kirby M. Evaluation of the clinical outcomes of switching patients from atorvastatin to simvastatin and losartan to candesartan in a primary care setting: 2 years on. International journal of clinical practice. 2008;62(3):480-4.

*Shows successful switching between patented atorvastatin and generic simvastatin - leading to considerable savings

20. Corrao G, Soranna D, Arfe A et al. Are generic and brand-name statins clinically equivalent? Evidence from a real data-base. European journal of internal medicine. 2014;25(8):745-50.

*Demonstartes similar effectiveness between generic and originator statins in routine clinical care

21. Sakshaug S, Furu K, Karlstad O, Ronning M, Skurtveit S. Switching statins in Norway after new reimbursement policy: a nationwide prescription study. British journal of clinical pharmacology. 2007;64(4):476-81.

22. Godman B, Bishop I, Finlayson AE, Campbell S, Kwon HY, Bennie M. Reforms and initiatives in Scotland in recent years to encourage the prescribing of generic drugs, their influence and implications for other countries. Expert review of pharmacoeconomics \& outcomes research. 2013;13(4):469-82.

**Shows high level of INN prescribing in Scotland across a range of products and classes, increase in high dose statins following quality measures and other initiatives, as well as a considerable improvement in prescribing efficiency with high use of low cost generic vs. patented statins

23. Godman B, Wettermark B, Hoffmann M, Andersson K, Haycox A, Gustafsson LL. Multifaceted national and regional drug reforms and initiatives in ambulatory care in Sweden: global relevance.

Expert review of pharmacoeconomics \& outcomes research. 2009;9(1):65-83.

24. Woerkom M, Piepenbrink H, Godman B et al. Ongoing measures to enhance the efficiency of prescribing of proton pump inhibitors and statins in The Netherlands: influence and future implications. Journal of comparative effectiveness research. 2012;1(6):527-38.

* Shows the successful impact of measures to obtain low prices for generics and enhance their use on overall statin expenditure 
25. Onwujekwe $\mathrm{O}$, Hanson $\mathrm{K}$, Ichoku H, Uzochukwu B. Financing incidence analysis of household out-of-pocket spending for healthcare: getting more health for money in Nigeria? Int J Health Plann Manage. 2014;29(2):e174-85.

26. Onah MN, Govender V. Out-of-Pocket payments, health care access and utilisation in SouthEastern Nigeria: A gender perspective. PLoS One. 2014;9(4):e93887.

27. Ewelukwa O, Onoka C, Onwujekwe O. Viewing health expenditures, payment and coping mechanisms with an equity lens in Nigeria. BMC Health Serv Res. 2013;13:87.

28. Odeyemi IA, Nixon J. Assessing equity in health care through the national health insurance schemes of Nigeria and Ghana: a review-based comparative analysis. Int J Equity Health. 2013;12:9. 29. Ezenduka C, Ubochi V, Ogbonna B. The Utilization Pattern and Costs Analysis of Psychotropic Drugs at a Neuropsychiatric Hospital in Nigeria. British Journal of Pharmaceutical Research. 2014;4(3):325-37.

30. Shrank WH, Hoang T, Ettner SL et al. The implications of choice: prescribing generic or preferred pharmaceuticals improves medication adherence for chronic conditions. Archives of internal medicine. 2006;166(3):332-7.

* Shows the interaction between compliance and patient co-payments

31. National Agency for Food and Drug Administration and Control (NAFDAC). GUIDELINES FOR REGISTRATION OF DRUGS AND RELATED PRODUCTS MANUFACTURED IN NIGERIA. 2014.

32. Federal Ministry of Health. Standard Treatment Guidelines,. Abuja, Nigeria2008.

33. Garuoliene K, Godman B, Gulbinovic J, Wettermark B, Haycox A. European countries with small populations can obtain low prices for drugs: Lithuania as a case history. Expert review of pharmacoeconomics \& outcomes research. 2011;11(3):343-9.

34. Simoens S. A reviewof generic medicine pricing in Europe. GaBI. 2012;1(1):8-12.

35. Godman B, Shrank W, Wettermark B et al. Use of Generics-A Critical Cost Containment Measure for All Healthcare Professionals in Europe. Pharmaceuticals 2010;3(8):2470-94.

36. Godman B, Ezenduka C, Bennie M, Persson M, Wladysiuk M, Barbui C. BARRIERS TO THE OPTIMAL USE OF PHARMACOTHERAPY TO MANAGE DEPRESSION AND SCHIZOPHRENIA: IMPLICATIONS AND FUTURE DIRECTION. Basic \& clinical pharmacology \& toxicology. 2014;115 (Suppl 1):180.

37. Fadare JO, Desalu O, Enwere OO, Sunmonu TO. Generic drug prescribing in Nigeria: knowledge, perceptions and attitudes of physicians First Training Workshop and Symposium MURIA Group July 2015: 37. Available at http://muria.nmmu.ac.za/Botswana-Workshop-and-Symposium27-29-July-2015/Abstracts.

38. Godman B, Bishop I, Campbell SM, Malmstrom RE, Truter I. Quality and efficiency of statin prescribing across countries with a special focus on South Africa; findings and future implications. Expert review of pharmacoeconomics \& outcomes research. 2015;15(2):323-30.

39. Feely J, Bennett K. Epidemiology and economics of statin use. Irish medical journal. 2008;101(6):188-91.

40. Opie LH, Dalby AJ. Cardiovascular prevention: lifestyle and statins--competitors or companions? South African medical journal.2014;104(3):168-73.

41. Baigent $C$, Keech A, Kearney PM et al. Efficacy and safety of cholesterol-lowering treatment: prospective meta-analysis of data from 90,056 participants in 14 randomised trials of statins. Lancet. 2005;366(9493):1267-78.

42. (WHO) WHO. Introduction to Drug Utilisation Research. WHO International Working Group for Drug Statistics Methodology, WHO Collaborating Centre for Drug Statistics Methodology, WHO Collaborating Centre for Drug Utilization Research and Clinical Pharmacological Services. ISBN 924 156234 X (NLM classification: WB 330). Available at URL:

http://www.who.int/medicines/areas/quality safety/safety efficacy/Drug\%20utilization\%20researc h.pdf2003. 
43. Vlahovic-Palcevski V, Gantumur M, Radosevic N, Palcevski G, Vander Stichele R. Coping with changes in the Defined Daily Dose in a longitudinal drug consumption database. Pharmacy world \& science.2010;32(2):125-9.

44. Mantel-Teeuwisse AK, Klungel OH, Schalekamp T, Verschuren WM, Porsius AJ, de Boer A. Suboptimal choices and dosing of statins at start of therapy. British journal of clinical pharmacology. 2005;60(1):83-9.

45. Civaner M. Sale strategies of pharmaceutical companies in a "pharmerging" country: the problems will not improve if the gaps remain. Health Policy.2012;106(3):225-32.

46. Godman B, Wettermark B, van Woerkom M et al. Multiple policies to enhance prescribing efficiency for established medicines in Europe with a particular focus on demand-side measures: findings and future implications. Frontiers in pharmacology. 2014;5:106.

47. Baumgartel $\mathrm{C}$. Myths, questions, facts about generic drugs in the EU. Generics and Biosimilars Initiative Journal (GaBI). 2012;1(1):34-8.

48. McGinn D, Godman B, Lonsdale J, Way R, Wettermark B, Haycox A. Initiatives to enhance the quality and efficiency of statin and PPI prescribing in the UK: impact and implications. Expert review of pharmacoeconomics \& outcomes research. 2010;10(1):73-85.

* of importance; ** of considerable importance 